\title{
An Aeroelastic Analysis of a Thin Flexible Membrane
}

\author{
Robert C. Scott* and Robert E. Bartels ${ }^{\dagger}$ \\ NASA Langley Research Center, Hampton, VA, 23681, USA \\ Osama A. Kandil ${ }^{\ddagger}$ \\ Old Dominion University, Norfolk, VA, 23529, USA
}

\begin{abstract}
Studies have shown that significant vehicle mass and cost savings are possible with the use of ballutes for aero-capture. Through NASA's In-Space Propulsion program, a preliminary examination of ballute sensitivity to geometry and Reynolds number was conducted, and a single-pass coupling between an aero code and a finite element solver was used to assess the static aeroelastic effects. There remain, however, a variety of open questions regarding the dynamic aeroelastic stability of membrane structures for aero-capture, with the primary challenge being the prediction of the membrane flutter onset. The purpose of this paper is to describe and begin addressing these issues. The paper includes a review of the literature associated with the structural analysis of membranes and membrane flutter. Flow/structure analysis coupling and hypersonic flow solver options are also discussed. An approach is proposed for tackling this problem that starts with a relatively simple geometry and develops and evaluates analysis methods and procedures. This preliminary study considers a computationally manageable 2-dimensional problem. The membrane structural models used in the paper include a nonlinear finite-difference model for static and dynamic analysis and a NASTRAN finite element membrane model for nonlinear static and linear normal modes analysis. Both structural models are coupled with a structured compressible flow solver for static aeroelastic analysis. For dynamic aeroelastic analyses, the NASTRAN normal modes are used in the structured compressible flow solver and 3rd order piston theories were used with the finite difference membrane model to simulate flutter onset. Results from the various static and dynamic aeroelastic analyses are compared.
\end{abstract}

\section{Introduction}

$\mathbf{N}$ ASA's new space exploration initiative has set a new course to develop human and robotic technologies that can deliver payloads larger than Apollo to the Moon, to Mars, and bring astronauts and samples safely back to Earth at costs much lower than Apollo. These challenges require creative aerospace systems. One proposed technology for safely delivering payloads to the surface of Mars and return samples to Earth involves flexible, deployable, perhaps inflatable decelerators like ballutes.

Studies have shown that significant vehicle mass and cost savings are possible with the use of ballutes for aerocapture. ${ }^{1}$ These deployable decelerators can be grouped into two general categories: trailing and clamped. The trailing ballute is characterized by an inflatable structure (typically a torus or sphere) connected to the payload aeroshell by tension lines. One such concept is shown in figure 1. For the clamped ballute, fabric fills the space between payload aeroshell

\footnotetext{
* Senior Aerospace Engineer, Aeroelasticity Branch, AIAA Associate Fellow.

†Senior Aerospace Engineer, Aeroelasticity Branch.

$\ddagger$ Professor, Department of Aerospace Engineering, AIAA Associate Fellow.
}

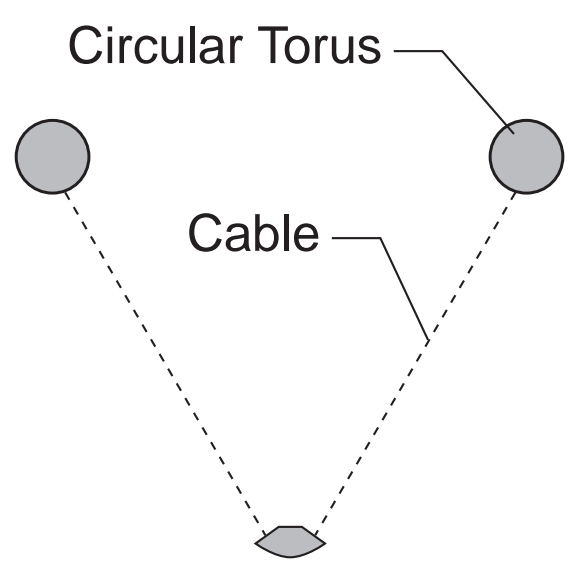

Fig. 1 Trailing ballute.

and the inflatable structure (torus). A concept for a clamped ballute is shown in figure 2 .

Through NASA's In-Space Propulsion (ISP) program,${ }^{2}$ a preliminary examination of ballute sensitivity to geometry and Reynolds number and the influence of large displacements on aeroheating and dynamic pressures was conducted. Computational Fluid Dynamic (CFD) studies have investigated the interaction of the spacecraft wake and aeroheating and their sensitivities 


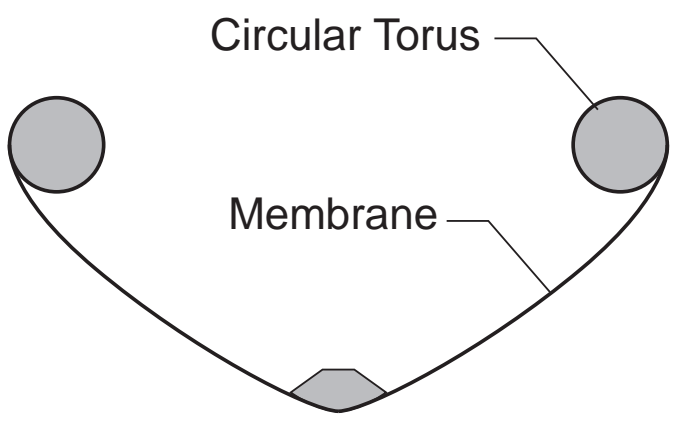

Fig. 2 Attached or clamped ballute.

to geometric and Reynolds number variations. ${ }^{3}$ These studies have revealed that various types of favorable and unfavorable shock interactions exist for the different ballute concepts. ${ }^{4}$ In addition, a single-pass coupling between an aero code and a finite element solver was used in reference 4 to assess static aeroelastic effects. It was found that the deformed shape allows for a circulation pattern within the flexible trough between the nose and the trailing edge. This deformation resulted in local increases and decreases in temperature and pressure along the aeroshell outer wall. Unsteady flow regions were also noted in some of the analyses. Aeroelastic stability was not considered.

A series of high speed wind-tunnel tests were also performed as part of the ISP program. ${ }^{5}$ Several wind-tunnel models were built out of plastic support structure and polyimide membranes to represent an attached ballute concept. Several membrane thicknesses and cone angles were tested up to Mach 10 and Reynolds number just over 525,000/foot. Some of the models exhibited significant unsteadiness and in some cases, flutter resulting in dynamic failure of the membrane. These results underscore the need to predict the static and dynamic aeroelastic response of these membrane structures.

Linear aeroelastic analysis methods are well understood and have long been applied to the aeroelastic analyses of relatively stiff lifting surfaces. Virtually all current aircraft, as well as, spacecraft such as the space shuttle have used these methods. Here, both the structure and flow field are analyzed using linear theories. The next level of improvement in fidelity of these methods is the use of nonlinear flow solvers, and a wide variety of CFD codes are available for the subsonic, supersonic, and hypersonic flight regimes. The use of a linear structural theory with a nonlinear CFD flow solver is adequate provided the structure is still relatively stiff and behaves linearly to the applied aeroloads. For ballutes and other membrane structures, aeroelastic analysis methods applicable to linear structures are not adequate. Nonlinear structural analysis methods are required.

The development of aeroelastic analysis methods for ballutes will involve several technical challenges: 1) modeling the complex nonlinear behavior of a membrane; 2) coupling a highly flexible structure to CFD codes; 3) the use of hypersonic flow solvers that have not previously been used for aeroelastic analysis; 4) validation of the structural modeling and the aeroelastic analysis method. Because of these challenges there have been very few aeroelastic analyses examining membrane structures.

There are many open questions regarding the dynamic aeroelastic analysis of ballutes and membrane structures. These questions include determining if a nonlinear structural analysis close-coupled to a suitable flow solver is required or whether a linear normal modes structural model similarly coupled is adequate to assess dynamic stability? What are the implications of static pressure difference and tension on membrane stability? How should the membrane be modeled if it is to be coupled with a flow solver? What are the time accuracy requirements of the hypersonic flow solver? Is the problem quasisteady/quasistatic with respect to the flow? The purpose of this paper is to begin the work of answering these questions. This preliminary study will consider a computationally manageable 2dimensional problem. The following will be discussed:

- Review of the literature associated with the structural analysis of membranes, membrane flutter, and hypersonic flow solver options.

- A proposed approach to tackling this problem that starts with a relatively simple geometry.

- A membrane finite difference model and discussion of model performance and convergence.

- Static analysis and comparison with a NASTRAN nonlinear solution.

- Static aeroelastic analyses.

- Preliminary dynamic aeroelastic analyses.

- Concluding remarks that include a discussion of accomplishments and deficiencies in this study as well as next steps.

\section{Membrane Literature Review}

This section of the paper will provide a review of the literature associated with the structural analysis of membranes, membrane flutter, and hypersonic flow solver options

\section{Membrane Structural Analysis}

The purpose of this section of the paper is to review the various ways in which membranes have been analyzed for various types of engineering problems. It is by no means a complete survey of the membrane 
structural analysis. References 6 and 7 provide a more detailed survey of nonlinear membrane analysis.

In the engineering field, the term membrane is reserved for zero bending rigidity structures. As with most areas of engineering the mechanics of membranes encompasses the use of both linear and nonlinear models. The applicability of the linearity assumption is very problem dependent. One such linear problem is the analysis of a stretched string or cable. This problem is essentially the same as the 2-dimensional membrane problem. The linearizing assumptions are that the out-of-plane displacements are small and the tension in the string remains close to its equilibrium value. ${ }^{8}$ These assumptions result in a linear, constantcoefficient partial differential equation that has been used directly in some of the earlier membrane flutter analyses. Unfortunately, the small deflection and constant tension assumptions are not likely to be applicable to the membrane flutter problem of a ballute.

Civil engineering has produced some work in the area of membrane analysis. One such problem is the analysis of guy cables. The study in reference 9 utilized a time-domain finite element approach to study large amplitude cable vibrations due to turbulent winds. Reference 10 considered the stability of a cable in incompressible flow where the bulk of the stability analysis was performed assuming constant tension. Other civil engineering membrane applications include membrane roofs and inflatable or pneumatic structures. ${ }^{11}$ While clearly nonlinear, such problems are primarily static in nature considering a constant velocity wind. Transient response to wind loads has also been considered but aeroelastic stability has not.

The aerodynamic analysis of sails is also relevant to the study at hand, and there exist several papers on aerodynamic sail theory. ${ }^{12-15}$ Typically these studies consider the sail to be an inextensible membrane for which a static shape and associated lift coefficient is sought. There have been some unsteady analyses, but aeroelastic stability had not been considered.

Somewhat similar to the analysis of sails is the study of membrane wings for micro air vehicles. Shyy et al have provided a number of papers on this topic. ${ }^{16-23}$ This work has focused on several key areas including the computation of aerodynamic coefficients, wing shape optimization, and aeroelastic response to turbulence and wind gusts. A key outcome of this work has been the development of approaches for coupled membrane-fluid dynamics analysis.

Another area where membranes have received considerable study has been the analysis of gossamer structures like space sails and scientific balloons. ${ }^{24-33}$ Some studies of gossamer structures have used commercial codes like NASTRAN and ABAQUS. One finding of these studies is that this class of mem- brane problems, where the membrane is initially underrestrained, can be very difficult to analyze using finite element methods. Reference 7 has an excellent discussion on the difficulties of analyzing membrane structures that undergo large displacements during loading. This type of structural system is underconstrained and stable equilibrium conditions only exist for loading fields that are orthogonal to the set of unstrained degrees of freedom. A common theme in the literature is that achieving a converged static nonlinear solution can be a challenge.

One of the real challenges of analyzing a membrane structure is that it tends to wrinkle as it can't sustain a compressive load. Considerable effort in recent years has been applied to enhance membrane modeling capabilities including membrane wrinkling, creases due to folds, and a variety of edge constraints, as well as nonlinear thermal effects. Methods of analysis and models that incorporate these effects are being developed within NASATRAN, ABAQUS, and other research codes. ${ }^{34}$

Obtaining a nonlinear static solution serves only as the first step in obtaining a flutter solution. A possible next step could be to use the stiffness matrices from a converged nonlinear static solution in a linear normal modes analysis. The resulting normal modes could be used within CFD codes in the usual manner. Reference 31 describes one such procedure for MSC/NASTRAN in which a nonlinear static solution for an inflatable structure is obtained then a linear normal modes analysis is performed. This approach described in reference 31 will be used in this study.

\section{Membrane Flutter Analysis}

While there are many papers on panel flutter and a variety of research efforts continues in this area, ${ }^{35,36}$ there are but a handful of papers that specifically address membrane flutter. Some of these studies consider the membrane flutter problem to be a limiting case of a plate as bending rigidity approaches zero or inplane tension approaches infinity. In discussing the effect of in-plane stress on panel flutter speed, Blisplinghoff and Ashley ${ }^{37}$ stated that for the limiting case of a membrane, when in-plane force approaches infinity, the flutter speed is infinite. Reference 38 presents a study of supersonic membrane flutter by considering the case of a two-dimensional plate in the presence of chordwise tensile in-plane stresses as the plate bending rigidity approaches zero. Reference 39 also considered the limiting case of a thin plate in supersonic flow. The analysis of reference 40 began with the membrane equation of a two dimensional membrane with a constant tension force and supersonic static aerodynamic approximation. One of the results of these studies has been the development of approximate flutter design 
criterion, but the applicability of these criteria to the ballute problem is limited, to say the least, due to the fact that these membranes were flat, linear, employed linear/simplified aerodynamic theories, and neglected static pressure difference across the membrane.

\section{Hypersonic Flow Solver Options}

Hypersonic panel flutter and hypersonic vehicle aeroservoelastic stability have been addressed through well established hypersonic aeroelastic analyses. The aerodynamic theories for these analyses has typically been classical or generalized linear and nonlinear piston theory, hypersonic small disturbance theory or the perturbed Euler method. ${ }^{41,42}$ These methods require the assumptions of a thin body and sharp leading edge and can be reasonably applied to lifting surfaces or sharp nosed bodies of revolution. Ballutes are bluff bodies and clearly violate these assumptions, thus these types aerodynamic theories are only suitable for preliminary examination of membrane flutter analysis strategies where the flow is approximately parallel to the membrane surface.

The ballute operating environment will span the rarified to continuum flow regimes, however, the highest loading is expected to be within the continuum flow regime. For dynamic aerothermoelastic analysis, there are a number of codes that can be considered for this effort. Two open source codes available from NASA Langley are LaURA ${ }^{43}$ and FUN3D. ${ }^{44}$ These codes have the appropriate aerothermodynamic models including equilibrium, non-equilibrium chemistry and surface catalycity. LaURA is not currently time accurate nor does it have a dynamic mesh capability. FUN3D is time accurate and has a dynamic mesh capability, and a modal capability has been recently added.

Another open source code available from NASA Langley is CFL3D. ${ }^{45-47}$ While this code lacks the aerothermodynamic analysis capabilities cited above, it is time accurate and has dynamic mesh and modal capabilities. While chemistry models would need to be added for accurate aerothermodynamic analysis, CFL3D may be suitable for initial assessment of close coupled membrane flutter analysis strategies.

\section{Flow/Structure Coupling}

The primary goal of this study is the prediction of the membrane flutter onset. This will require that appropriate aerodynamic theories or codes be coupled with a suitable structural analysis tool. The computational strategies can be grouped into essentially two broad categories: 1) Loose coupling, and 2) Close coupling. This section of the paper will provide a brief discussion of these approaches. In general, the same types of flow and structural solvers can be used in both strategies. Typically, a loose coupled analysis is solved with the flow and structural parts of the problem in disparate domains. If time accuracy is preserved, close coupled analysis can also solve the flow and structure in disparate domains, or alternatively, the governing equations can be combined and the problem solved simultaneously. The decision to combine all parts of the analysis into a single code is often based on convenience or, in the case of commercial codes, the availability of the source code. The primary difference between the two approaches is that loose coupling is not time accurate while close coupling is. This means that a loose coupled strategy is suitable for static aeroelastic calculations only, while close coupling can be used for static or dynamic analyses. Table 1 lists the similarities and differences between the two strategies. For a more detailed discussion of computational approaches see reference 48 .

Table 1 Flow/Structure coupling strategies.

\begin{tabular}{ccc}
\hline \hline Feature & Loose Coupled & Close Coupled \\
\hline Time Accurate & No & Yes \\
Flow/Struct- & Disparate & $\begin{array}{c}\text { Disparate } \\
\text { Unified }\end{array}$ \\
Flow Solver & Any & Any \\
Struct Solver & Linear & Linear \\
& Nonlinear & Nonlinear \\
Code & Separate* & Separate \\
& Combined & Combined \\
Flow/Struct- & Interpolated & Interpolated \\
Interface & Same Grid & Same Grid \\
Aeroelasticity & Static & Static \\
& & Dynamic \\
\hline \hline
\end{tabular}

This paper will describe several modeling and analysis procedures. These include: 1) A finite difference model coupled with CFD for static aeroelastic analysis; 2) A finite difference model coupled with piston theory for static and dynamic aeroelastic analysis; 3 ) A NASTRAN finite element model coupled with CFD for static aeroelastic analysis; and 4) A modal structural model coupled with CFD for dynamic aeroelastic analysis. It will be helpful and descriptve to discuss where each of these fits into the loose/close coupling framework described above.

A finite difference structural model of a membrane will be described. This structural model is nonlinear and will be used with CFL3D in a loosely coupled 
manner for static aeroelastic calculations in which the CFD surface grid and the structural grid are not coincident and interpolation is used to pass information between the two domains. This nonlinear structural model will also be used with piston theory in a close coupled manner in which the structure is nonlinear and solved simultaneously with the aerodynamics on the same grid.

A finite element model (FEM) will also be described in which two solution procedures will be used: nonlinear static and linear normal modes. For the static aeroelastic analysis, this FEM will be used with a nonlinear static solution procedure and loosely coupled with CFL3D for static aeroelastic calculations in which the CFD surface grid and the structural grid are not coincident and interpolation is used to pass information between the two domains. Following the nonlinear static solution, the FEM will be used with a linear normal modes solution procedure to generate natural frequencies and mode shapes that will be passed via interpolation to CFL3D. Here the flow and modal structural model are solved in a close coupled manner within the same code, but in disparate domains. Here, the dynamic structural analysis is linear.

\section{Approach}

The dynamic aeroelastic analysis of a thin-film ballute will be a complex task. To determine flutter onset, a time marching close-coupled solution of the hypersonic flow field and structural dynamics of a detailed thin-film structural model may be required. The structural analysis will be nonlinear and may also need to be capable of modeling wrinkles. It is hoped that a modal approach may be adequate, but a fully coupled analysis or experimental data will be needed to determine if and when the modal approach can be used. This study will attempt to improve our understanding of aeroelastic membrane analysis by studying the simplest possible configuration. The following steps are proposed:

- Develop Finite Difference (FD) membrane structural model including first order piston theory aerodynamics. Evaluate stability and convergence properties of scheme. An advantage of the FD model is it may be relatively easy to add it to an existing CFD code. It may also be useful or necessary to develop a nonlinear time accurate membrane finite element model as an alternative approach, but this approach was not taken in the present study.

- Statically validate FD structural model with nonlinear finite element analysis. This finite element analyses should include commercial codes like NASTRAN, as well as, research codes. NASTRAN was used in the present study.

- Dynamically validate FD structural model with appropriate finite element analysis and theoretical solutions where available.

- Static aeroelastic analysis: Perform static aeroelastic analyses where Mach number, altitude, static pressure difference and pretension are varied. Examine convergence properties of the FD scheme.

- Static aeroelastic analysis: Perform static aeroelastic analyses where Mach number, altitude, static pressure difference and pretension are varied. Examine convergence properties of the FD scheme.

- Dynamic aeroelastic analysis: This should include fully coupled flutter analysis compared with a modal flutter analysis. The fully coupled analysis will initially be the FD model but could also include a nonlinear time accurate finite element analysis.

- Apply higher fidelity aerodynamic methods to the 2-dimensional membrane problem. Initially, the CFL3D code is used as it has all the necessary features for the aforementioned comparison: time-accuracy, aeroelastic grid deformation scheme, and a modal capability. Later this could include an appropriate hypersonic code.

- Examine a 3-dimensional, nominal flat membrane using piston theory.

- Examine a 3-dimensional, nominal flat membrane using CFL3D and other hypersonic CFD codes.

- It is hoped that this building block approach could eventually lead to the development of an analysis capability and suitable experience base for the analysis and design of a 3-dimensional ballute structure.

\section{Finite Difference Membrane Model}

The problem considered in this study will be that of a 2-dimensional membrane in the presence of supersonic flow. The problem is shown in figure 3 and looks similar to the classical panel flutter problem. The membrane properties to be considered in this study are listed below,

$\begin{array}{cc}E & 800,000 \mathrm{psi} \\ L & 10 \mathrm{in} \\ h & 0.001 \mathrm{in} \\ \rho_{m} & 0.0015945 \mathrm{slug} / \mathrm{in}^{3}\end{array}$




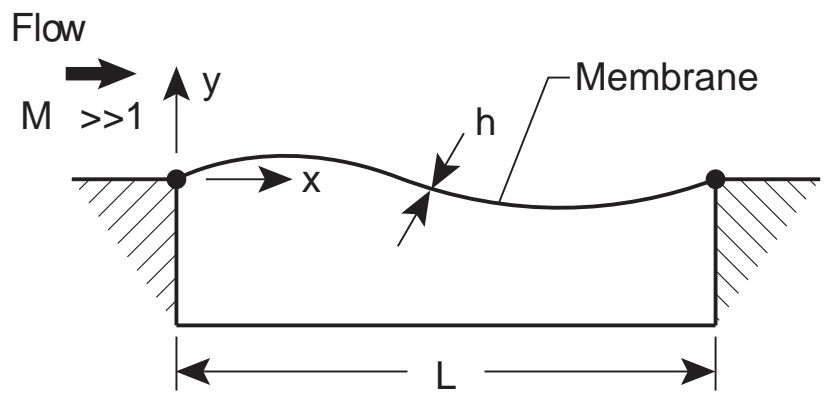

Fig. 3 Two dimensional membrane.
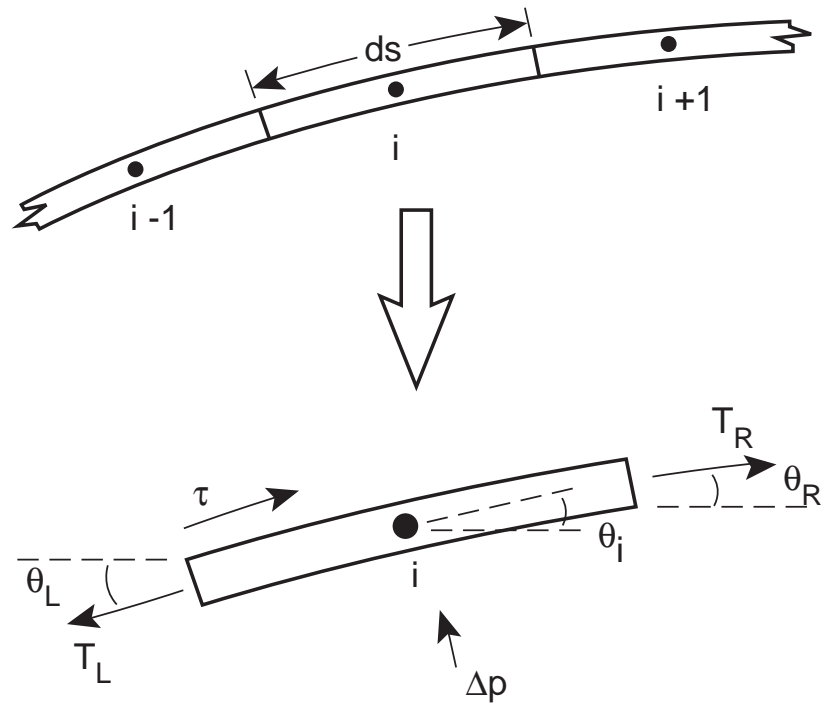

Fig. 4 Membrane model and membrane segment forces.

\section{Structural Equations of Motion}

The linear equation for a 2 - $\mathrm{d}$ membrane is

$$
\rho_{m} h \frac{\partial^{2} w}{\partial t^{2}}-T \frac{\partial^{2} w}{\partial x^{2}}+\Delta p=0
$$

Here, deformation in the $\mathrm{x}$-direction is ignored and the $\mathrm{y}$-direction or out-of-plane deformation $(w)$ is assumed sufficiently small that the tension $(T)$ is approximately constant. The natural frequencies of this system are obtained by separation of variables with the pressure difference across the membrane set to zero $(\Delta p=0)$ where $n=1,2,3, \ldots$

$$
f_{n}=\frac{n \sqrt{\frac{T}{\rho_{m} h}}}{2 L}
$$

This result will be used for some comparisons between the FD scheme and linear theory later in the paper.

For the case of nonlinear equations of motion for the membrane, we consider the balance of forces of the membrane segment shown in figure 4 . Here, in the $\mathrm{x}$-direction we obtain the following,

$$
\begin{array}{r}
-T_{L} \cos \theta_{L}+T_{R} \cos \theta_{R}-\Delta p d s \sin \theta_{i}+ \\
\tau d s \cos \theta_{i}=\rho_{m} h d s \ddot{x}
\end{array}
$$

and for the y-direction,

$$
\begin{array}{r}
-T_{L} \sin \theta_{L}+T_{R} \sin \theta_{R}+\Delta p d s \cos \theta_{i}+ \\
\tau d s \sin \theta_{i}=\rho_{m} h d s \ddot{y}
\end{array}
$$

where,

$$
\begin{gathered}
\cos \theta_{L}=\frac{x_{i}-x_{i-1}}{\sqrt{\left(x_{i}-x_{i-1}\right)^{2}+\left(y_{i}-y_{i-1}\right)^{2}}} \\
\cos \theta_{R}=\frac{x_{i+1}-x_{i}}{\sqrt{\left(x_{i+1}-x_{i}\right)^{2}+\left(y_{i+1}-y_{i}\right)^{2}}} \\
\sin \theta_{L}=\frac{y_{i}-y_{i-1}}{\sqrt{\left(x_{i}-x_{i-1}\right)^{2}+\left(y_{i}-y_{i-1}\right)^{2}}} \\
\sin \theta_{R}=\frac{y_{i+1}-y_{i}}{\sqrt{\left(x_{i+1}-x_{i}\right)^{2}+\left(y_{i+1}-y_{i}\right)^{2}}} \\
d s=\frac{1}{2} \sqrt{\left(x_{i+1}-x_{i-1}\right)^{2}+\left(y_{i+1}-y_{i-1}\right)^{2}} \\
\sin \left(\theta_{i}\right)=\frac{\frac{1}{2}\left(y_{i+1}-y_{i-1}\right)}{d s} \\
\cos \left(\theta_{i}\right)=\frac{\frac{1}{2}\left(x_{i+1}-x_{i-1}\right)}{d s}
\end{gathered}
$$

To simplify expressions that will appear later in this paper we define the membrane length on the left and right of the $\mathrm{i}^{\text {th }}$ point as,

$$
\begin{aligned}
& \ell_{L_{i}}=\sqrt{\left(x_{i}-x_{i-1}\right)^{2}+\left(y_{i}-y_{i-1}\right)^{2}} \\
& \ell_{R_{i}}=\sqrt{\left(x_{i+1}-x_{i}\right)^{2}+\left(y_{i+1}-y_{i}\right)^{2}}
\end{aligned}
$$

If the membrane material is linear elastic, the left and right tension terms for the ith membrane segment can be approximated as,

$$
T_{L_{i}}=
$$$$
E h \frac{\sqrt{\left(x_{i}-x_{i-1}\right)^{2}+\left(y_{i}-y_{i-1}\right)^{2}}-\Delta x_{o}(1-\alpha \Delta T)}{\Delta x_{o}}
$$

$$
\begin{gathered}
T_{R_{i}}= \\
\operatorname{Eh} \frac{\sqrt{\left(x_{i+1}-x_{i}\right)^{2}+\left(y_{i+1}-y_{i}\right)^{2}}-\Delta x_{o}(1-\alpha \Delta T)}{\Delta x_{o}}
\end{gathered}
$$


where $\Delta x_{o}$ is the undeformed or initial length of the ith membrane segment. The term $\alpha \Delta T$ represents the thermal expansion coefficient and the temperature change that, for this implementation, are selected arbitrarily to obtain a desired value of pretension in the membrane. Only positive values of tension are permitted, so negative values are set to zero, and the ability of this modeling approach to capture wrinkling is an open question.

The nonlinear model to be developed in this section of the paper will be based on finite difference expressions. Finite difference representations for the acceleration of the $\mathrm{i}^{\text {th }}$ point in the $\mathrm{x}$ and $\mathrm{y}$ directions are

$$
\ddot{x}_{i}=\frac{x_{i}^{n+1}-2 x_{i}^{n}+x_{i}^{n-1}}{(\Delta t)^{2}}
$$

and,

$$
\ddot{y}_{i}=\frac{y_{i}^{n+1}-2 y_{i}^{n}+y_{i}^{n-1}}{(\Delta t)^{2}}
$$

where $\Delta t$ is the time step. Using these and the expressions developed previously, an implicit finite difference expression can be developed. Equations 3 and 4 can be rewritten as shown in equations 18 and 19 (see bottom of next page) where,

$$
\nu=\frac{(\Delta t)^{2}}{\rho_{m} h \Delta x}
$$

The parameter $\nu$ has the appearance of a Courant number used in the Courant-Friedrichs-Lewy (CFL) condition that defines scheme stability limits on time step and spatial mesh spacing. Equations 18 and 19 form tridiagonal matrices that can be solved using Thomas's algorithm.

\section{Finite Element Membrane Model}

As mentioned earlier, one of the objectives of this study is to assess the applicability of using a modal approach for membrane and ultimately thin film ballute flutter analysis. While research codes may have the latest algorithms and other unique capabilities, they often lack the library of elements and features necessary to model complex structures. As such, NASTRAN will be utilized here as it has the capability to perform nonlinear static solutions and then perform a modal restart to obtain linear mode shapes and frequencies for conventional flutter analysis.

The membrane finite element model is shown in figure 5. It is modeled using CQUAD4 elements with suitable boundary conditions and properties to achieve 2-dimensional behavior. The membrane material is modelled as orthotropic with the Poisson ratio and the z-direction thermal expansion coefficient set to zero.

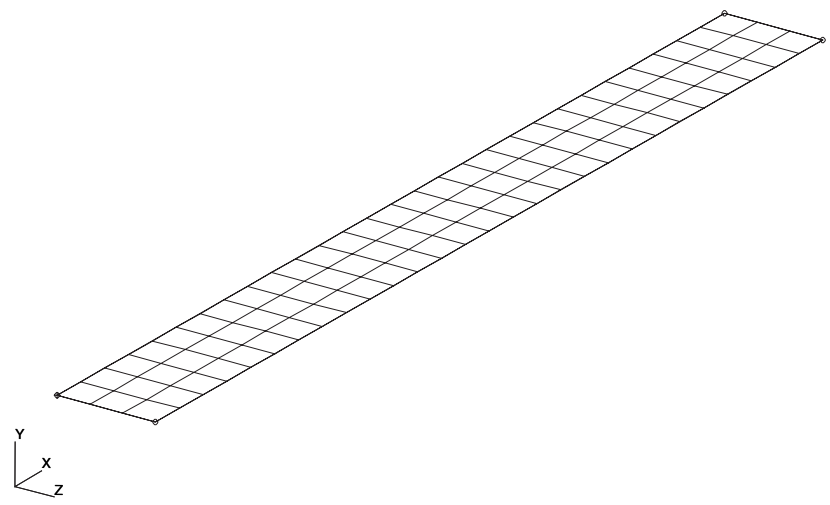

Fig. 5 NASTRAN membrane model.

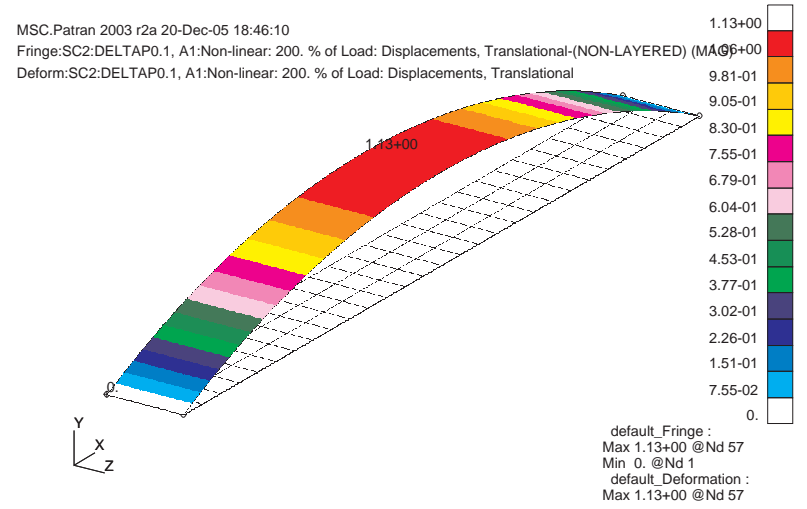

Fig. 6 NASTRAN nonlinear static solution, $\Delta P_{o}=2.5 \mathrm{psi}$ and Pretension $=2 \mathrm{lbf} / \mathrm{in}$.

The NASTRAN nonlinear static solution (SOL 106) essentially performs a series of analyses where the load is incrementally increased to the desired level. It was found here that since the membrane is initially flat and very thin a very small load increment is required at the start of the analysis or the solution will fail. Once there is some deformation in the membrane due to the static pressure load, the membrane stiffness increases and a larger load increment can be applied. As with the finite difference model, the pretension is included in the analysis via an arbitrary value of thermal expansion coefficient and temperature change. Figure 6 shows an example of a converged NASTRAN SOL 106 (nonlinear static) solution.

\section{Preliminary Static and Dynamic Membrane Analyses}

The purpose of this section of the paper is to present the results of the authors attempts to learn how to use the finite difference membrane model described earlier. This is done prior to the introduction of aerodynamic forces. Stability, convergence, and dynamic behavior of the finite difference membrane model are considered. Finite difference analyses are compared with linear theory or finite element analyses for the purpose 
of validation.

The analyses of the membrane comprises two phases: obtaining a converged static solution followed by a dynamic analysis. The solution procedure for both phases is largely the same; a time-marching analysis is conducted until convergence is obtained or in the case of the dynamic analysis, until stability can be assessed. In either case, scheme stability is a concern and the $\nu$ parameter identified earlier in equation 20 is similar to the Courant number commonly encountered in numerical schemes. A similar parameter was identified in reference 18 where a similar but less general modeling approach was taken. Typically, there are upper limits on the value of $\nu$ for scheme stability.

For the values of $h$ and $\rho_{m}$ considered here, $\Delta x$ was held constant at $0.5 \mathrm{in}$, and $\Delta t$ was varied to identify an upper limit for scheme stability. A value of $10^{-6}$ was ultimately found to be approximately the upper limit for stability. Inclusion of sub-iterations in future versions of this finite difference model may allow for larger time steps. For the flat membrane, the static converged solution is not necessary, but an initial displacement perturbation is required. For this and subsequent analyses, the initial deflection for the dynamic finite difference analyses is

$$
\begin{aligned}
y_{\text {initial }}=y_{\text {static }} & +0.001[\sin (x \pi / L) \\
& +\sin (2 x \pi / L)+\sin (3 x \pi / L)]
\end{aligned}
$$

where $y_{\text {static }}$ is the converged static solution. For the special case of $\Delta P=0$, the membrane is flat and $y_{\text {static }}$ is zero.

Figure 7 shows the time history traces of all the membrane segment centers for the case of a flat membrane $(\Delta P=0)$. Here, we can see that the solution is stable but has little damping. Spectral analysis of these time traces was performed to identify natural frequencies. These frequencies are listed in table 2 where they are compared with the theoretical linear frequencies (equation 2). While not identical, the frequencies are consistent and indicate that no obvious implementation errors are present in the finite difference model.

The lack of significant damping previously identified is good in the sense that the numerical scheme appears

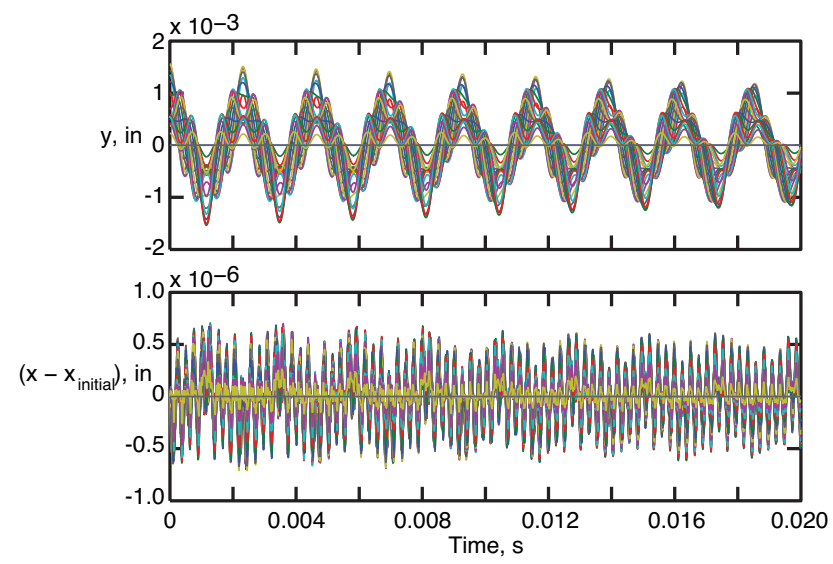

Fig. 7 Time histories of membrane segment centers for a flat membrane, $\Delta x=0.05 i n, \Delta P=$ $0.0 \mathrm{psi}$, and Pretension $=10 \mathrm{lbf} / \mathrm{in}$.

Table 2 Comparison of modal frequencies (Hz.) for a flat membrane. $\Delta P=0 p s i$ and Pretension $=10 \mathrm{lbf} / \mathrm{in}$.

\begin{tabular}{ccc}
\hline \hline Mode & Linear Theory & Finite Difference \\
\hline 1 & 475 & 430 \\
2 & 950 & 859 \\
3 & 1,425 & 1,289 \\
\hline \hline
\end{tabular}

to not be adding any, but the lack of damping is undesirable in terms of obtaining a statically converged solution. An additional concern in getting a converged static solution is the small size of the time step that must be used. Fortunately, for static solutions there are a couple of obvious ways that convergence can be improved. One way is to add some type of real or artificial damping to minimize dynamic oscillations. Using first-order-accurate estimates of the membrane segment center velocities in the $\mathrm{x}$ and $\mathrm{y}$ directions, the following terms are added to the right hand side of equations 18 and 19 to add damping,

$$
0.035 \nu \frac{x_{i}^{n}-x_{i}^{n-1}}{\Delta t}
$$

$x_{i+1}^{n+1} \nu\left(\frac{T_{R_{i}}^{n}}{\ell_{R_{i}}^{n}}+\frac{\tau}{2}\right)+x_{i}^{n+1}\left(\nu\left(-\frac{T_{L_{i}}^{n}}{\ell_{L_{i}}^{n}}-\frac{T_{R_{i}}^{n}}{\ell_{R_{i}}^{n}}\right)-1\right)+x_{i-1}^{n+1} \nu\left(\frac{T_{L_{i}}^{n}}{\ell_{L_{i}}^{n}}-\frac{\tau}{2}\right)=-2 x_{i}^{n}+x_{i}^{n-1}+\nu \Delta p \frac{1}{2}\left(y_{i+1}-y_{i-1}\right)$

$y_{i+1}^{n+1} \nu\left(\frac{T_{R_{i}}^{n}}{\ell_{R_{i}}^{n}}+\frac{\tau}{2}\right)+y_{i}^{n+1}\left(\nu\left(-\frac{T_{L_{i}}^{n}}{\ell_{L_{i}}^{n}}-\frac{T_{R_{i}}^{n}}{\ell_{R_{i}}^{n}}\right)-1\right)+y_{i-1}^{n+1} \nu\left(\frac{T_{L_{i}}^{n}}{\ell_{L_{i}}^{n}}-\frac{\tau}{2}\right)=-2 y_{i}^{n}+y_{i}^{n-1}-\nu \Delta p \frac{1}{2}\left(x_{i+1}-x_{i-1}\right)$ 

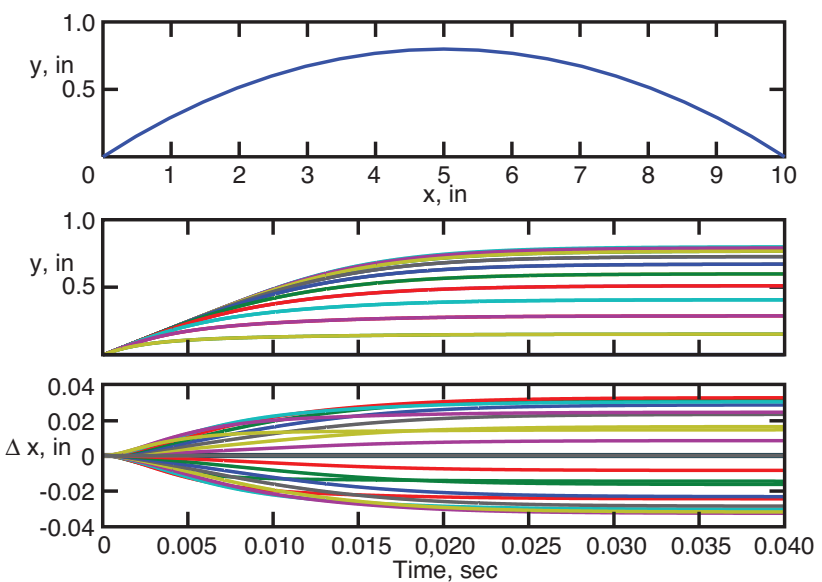

Fig. 8 Converged membrane solution and time histories of membrane segment centers obtained with artificial structural damping and material density, $\Delta x=0.05 i n, \Delta P=1.0 \mathrm{psi}$, and Pretension $=$ $2.5 \mathrm{lbf} / \mathrm{in}$.

$$
0.035 \nu \frac{y_{i}^{n}-y i^{n-1}}{\Delta t}
$$

The other way to increase convergence is to artificially increase the value of the material density so that a larger time step can be used for a given value of $\nu$. This is a viable option as $\rho_{m}$ does not influence the static solution, so the density can be increased by several orders of magnitude allowing the time step size to be similarly increased. With these modifications, a converged static solution is easily obtained as shown by the membrane segment center time traces in figure 8. For subsequent dynamic analysis, the damping terms must be eliminated and nominal value of density must be used. These methods of improving static convergence will be used throughout the remainder of this paper.

To further validate the finite difference model, converged static analyses can be compared with converged NASTRAN SOL 106, nonlinear static solutions. For the finite difference and NASTRAN analyses, the final converged solutions for the case of $\Delta P=1.0 \mathrm{psi}$ and Pretension $=5 \mathrm{lbf} / \mathrm{in}$ are shown in figure 9 . The NASTRAN and the finite difference solutions are all in excellent agreement, further indicating that the finite difference membrane model is valid.

The final comparison to be made in this section of the paper will be between the natural frequencies of the finite difference scheme with those obtained using NASTRAN. In the case of the NASTRAN, the appropriate frequencies are obtained by performing a SOL 103, normal modes analysis, using the stiffness matrix from the appropriate converged SOL 106, nonlinear static solution. The finite difference frequencies are calculated by first obtaining a converged static solution, followed by a dynamic analysis using the

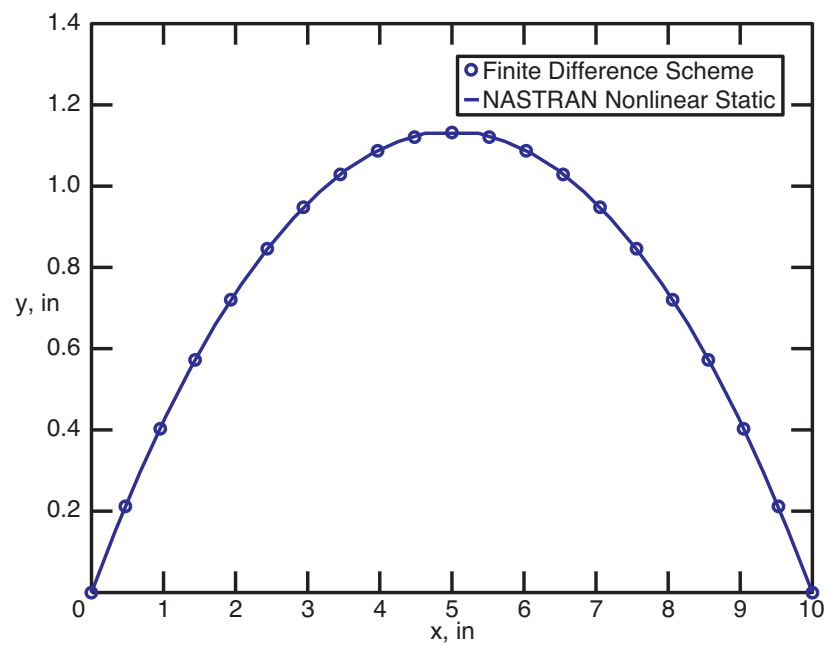

Fig. 9 Comparison of finite difference and NASTRAN SOL 106 membrane displacement, $\Delta P=$ $2.5 \mathrm{psi}$ and Pretension $=5 \mathrm{lbf} / \mathrm{in}$.

methods described above. Then, spectral analysis of the time traces is used to identify modal frequencies. The first three frequencies using each analysis method are shown in table 3. The excellent comparison further validates the finite difference scheme.

Table 3 Comparison of modal frequencies (Hz.), $\Delta P=1.0 \mathrm{psi}$ and Pretension $=10 \mathrm{lbf} / \mathrm{in}$.

\begin{tabular}{ccc}
\hline \hline Mode & NASTRAN & Finite Difference \\
\hline 1 & 825 & 820 \\
2 & 1,177 & 1,172 \\
3 & 1,792 & 1,797 \\
\hline \hline
\end{tabular}

\section{Aerodynamic Modeling}

So far, $\Delta P$ has been considered a static quantity. Here and throughout the remainder of the paper, $\Delta P$ will be defined as the sum of an unsteady component and a static component $\left(\Delta P_{o}\right)$. The unsteady component of $\Delta P$ is a function of the structural displacement of the membrane. Two methods will be used to calculate the unsteady part of $\Delta P$ : piston theory and CFD. Piston theory has the advantage that it is simple and can be easily incorporated into the finite difference scheme already described. When properly applied, CFD analysis is more accurate than piston theory, and codes like CFL3D can model structural dynamics modally.

Piston theory is a simple inviscid unsteady aerodynamic theory that has been used extensively in supersonic and hypersonic aeroelasticity. It provides a point-function relationship between the local pressure on the surface and the local fluid velocity normal to the surface. The derivation of piston theory utilizes the isentropic expression for the pressure on the sur- 
face of a moving piston.

$$
\frac{p(x, t)}{p_{\infty}}=\left(1+\frac{\gamma-1}{2} \frac{v_{n}}{a_{\infty}}\right)^{\frac{2 \gamma}{(\gamma-1)}}
$$

where $\gamma$ is the ratio of specific heats and $a_{\infty}$ is the free stream sonic speed. The normal velocity is

$$
v_{n}=\frac{\partial w}{\partial t}+V_{\infty} \frac{\partial w}{\partial x}
$$

where $w$ is the out of plane displacement. The expression for piston theory is based on a binomial expansion of equation 24. A third order expansion can be written as follows ${ }^{49}$

$$
\begin{aligned}
p(x, t)-p_{\infty}=p_{\infty}\left[\gamma\left(\frac{v_{n}}{a_{\infty}}\right)\right. & +\frac{\gamma(\gamma+1)}{4}\left(\frac{v_{n}}{a_{\infty}}\right)^{2} \\
& \left.+\frac{\gamma(\gamma+1)}{12}\left(\frac{v_{n}}{a_{\infty}}\right)^{3}\right]
\end{aligned}
$$

For implementation into the finite difference scheme, equation 25 will be rewritten,

$$
\left(v_{n}\right)_{i}=\frac{y_{i}^{n}-y_{i}^{n-1}}{\Delta t}+V_{\infty} \frac{y_{i+1}^{n}-y_{i-1}^{n}}{x_{i+1}^{n}-x_{i+1}^{n}}
$$

and with the addition of a static pressure difference, the $\Delta P$ term in equations 3 and 4 is

$$
\Delta p=\left(p(x, t)-p_{\infty}\right)+\Delta p_{o}
$$

Equations 26, 27, and 28 can be easily included in the finite difference model. Static and dynamic aeroelastic analysis using piston theory will be presented in a subsequent section of the paper.

The alternative approach for calculating $\Delta P$ is to use CFD. The CFD code CFL3D version 6.4 (CLF3Dv6.4) $^{45,46}$ will also be used in this study. CFL3D solves the time-dependent conservation law form of the Reynolds-averaged Navier-Stokes equations using a finite-volume approach. Upwind-biasing is used for the convective and pressure terms while central differencing is used for the shear stress and heat transfer terms. Implicit time advancement is used with the ability to solve steady or unsteady flows. In this study, the Euler equations were solved. Using MATLAB m-file scripts, CFL3D can be loosely coupled with both the finite difference and the NASTRAN membrane models for static aeroelastic analysis. For dynamic aeroelastic analysis, CFL3D currently only supports a modal representation of structures, and MATLAB m-file scripts were again used to loosely connect the two codes. These procedures will be discussed in more detail in the sections that follow.

One final note about the aerodynamic model. In this study, analyses will be performed at constant Mach number with altitude being varied. An atmosphere model, curve fit of a standard atmosphere, ${ }^{50}$ was used to calculate the temperature and density associated with a given altitude so that dynamic pressure and free stream velocity could also be calculated. This aerodynamic model was used throughout this study, with both piston theory and CFD.

\section{Membrane Static Aeroelasticity}

This section of the paper will examine the static aeroelastic behavior of 2-d membranes. First, a loose CFD coupling procedure will be described followed by a discussion of results.

\section{Structural/CFD Coupling for Static Aeroelasticity}

A procedure was implemented to loosely couple CFL3D with both the NASTRAN or the finite difference membrane model. For this analysis two procedures had to be developed. One was to pass the pressure coefficient data from the CFD output to the input of the structural analysis. The other requires that the output of the structural analysis (nodal displacements) be passed to the CFD code. These procedures were performed using MATLAB scripts (m-files). The details of these two procedures will be described here.

To transfer pressures to the structural analysis input, the pressure coefficients were read from a CFL3D output file (cfl3d.prout). These coefficients were converted to pressures using the dynamic pressure appropriate for the Mach number and altitude being examined, and the resulting pressures were then interpolated to the structural mesh using linear interpolation. In the case of the finite difference analysis, these fixed pressures were then used in the time-marching membrane solution. For the NASTRAN analysis, a script was used to generate a bulk data file (.bdf) containing PLOAD2 cards. This pressure data file was used in the NASTRAN SOL 106 analysis by way of an include statement in the main input deck.

To transfer the structural displacements to the CFD analysis, a script was used to interpolate the structural displacements to the CFD computational surface grid points. In the case of the finite difference model, the structural displacements are available within the MATLAB environment, and in the case of the NASTRAN solution, the displacements are read from the .f06 output file. The structural displacements are then interpolated to the CFD grid points and written to the file newsurf.p3d. Within the CFL3D input file, the keyword idef_ss is set to unity which forces CFL3D to read the newsurf.p3d file and deform the grid accordingly.

While the static analysis is relatively straight forward with the aforementioned procedures being repeated one after the other until convergence, there are a couple of additional items of interest that should 


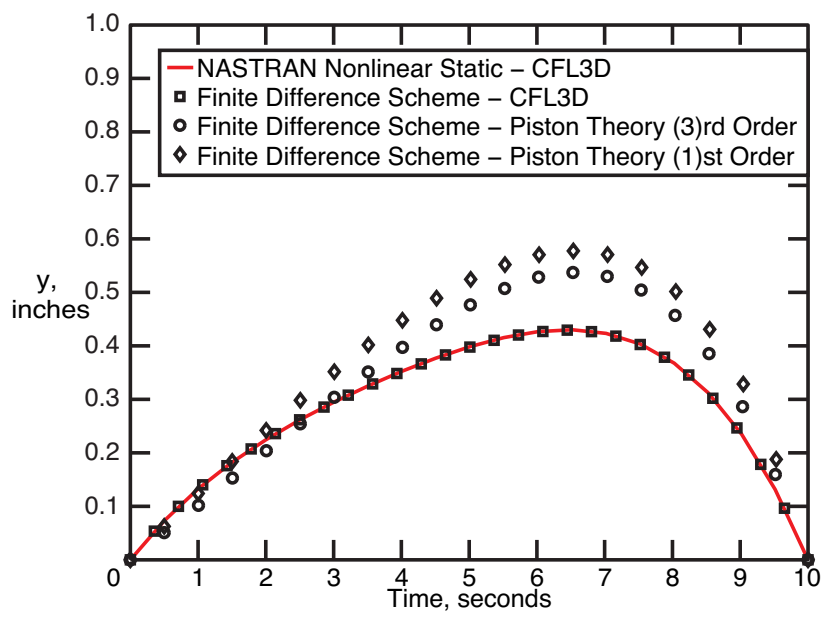

Fig. 10 NASTRAN nonlinear static aeroelastic solution and finite difference aeroelastic solution using CFL3D and piston theory, $M=5.0$, Altitude $=$ 60,000feet, $\Delta P_{o}=1.0 \mathrm{psi}$, and Pretension $=$ $10 \mathrm{lbf} / \mathrm{in}$.

be considered. One of these was the use of a relaxation factor that governs the portion of the structural displacement from each iteration that is carried forward. For the Mach number considered, no relaxation was needed (relaxation was unity) for all the finite difference/CFD analyses and for the NASTRAN/CFD analyses when the altitude was at or above 60,000 feet. Below this altitude, the NASTRAN/CFD analyses required a very small value of relaxation (0.05) to achieve convergence. Finally, it should be pointed out that the CFD grids used here were relatively simple, so they were all generated using a MATLAB script.

\section{Static Aeroelastic Analyses}

The first set of data to be examined will be a comparison of all the static aeroelastic analysis methods described in this paper. This includes the finite difference membrane model with both 1st and 3rd order piston theory and CFD. Results obtained from the NASTRAN/CFD procedure will also be considered. Figure 10 shows a comparison of the converged static aeroelastic analyses of the various approaches at an altitude of 60,000 feet. A significant observation is the continued excellent agreement between the NASTRAN SOL 106 and the finite difference analysis when the same aerodynamic method is used. It is also noted that piston theory provides results consistent with CFL3D, and as expected, 3rd order piston theory provides a result closer to the CFD analysis than does 1st order piston theory. First order piston theory will no longer be considered in this study.

Figure 11 shows the results of a series of finite difference/piston theory static aeroelastic analysis for $M=5.0$ where altitude is varied from 200,000 feet to sea level. The highest altitude conditions repre-

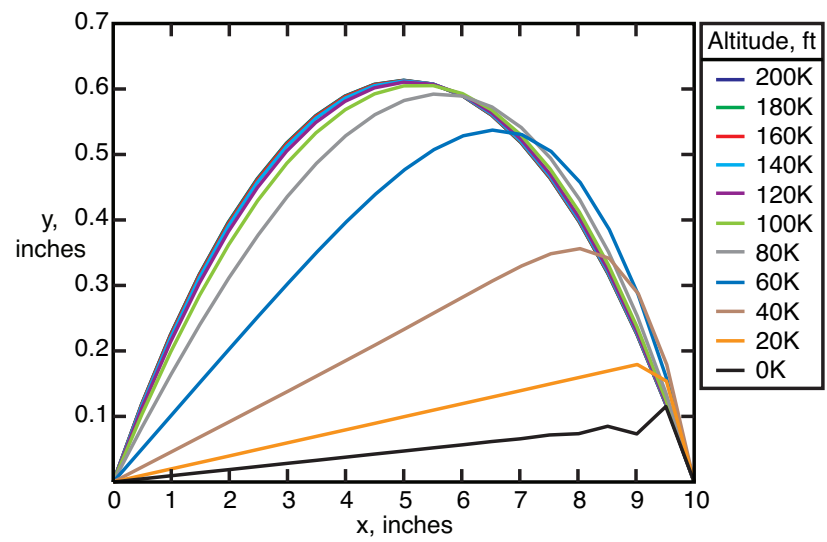

Fig. 11 Static aeroelastic solutions obtained using the finite difference membrane model and 3rd order piston theory aerodynamics, $M=\mathbf{5 . 0}$, Pretension $=10 \mathrm{lbf} / \mathrm{in}, \Delta P_{o}=1.0 \mathrm{psi}$, and $\Delta x=0.05$ in.

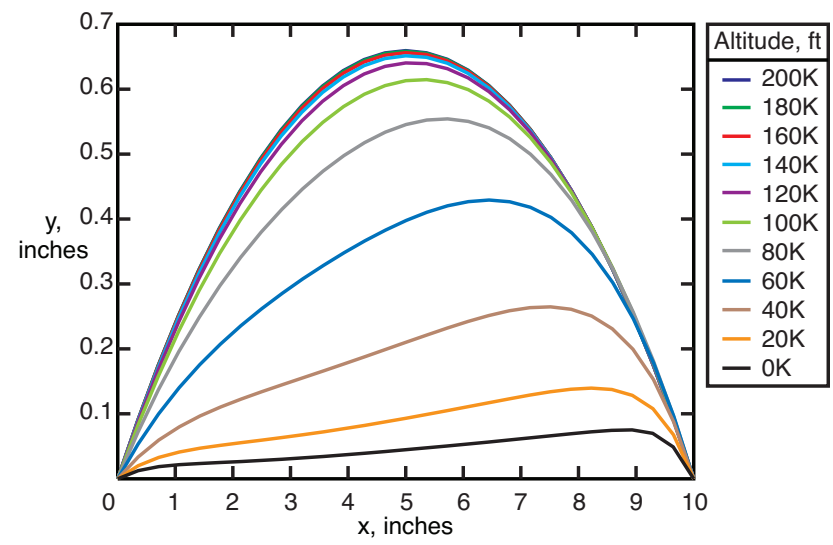

Fig. 12 NASTRAN nonlinear static aeroelastic solution with CFL3D Euler aerodynamics, $M=$ 5.0, $\Delta P_{o}=1.0 \mathrm{psi}$, and Pretension $=10 \mathrm{lbf} / \mathrm{in}$.

sent very low dynamic pressures and the solutions are nearly symmetric and similar to those obtained previously. As altitude is reduced, increasing the dynamic pressure, the converged deflections appear to flatten out due to the increasing aerodynamic load. At the lowest altitudes, the deflected membrane appears wrinkled. The results from a similar series of NASTRAN/CFD static analysis are shown in figure 12 . The trends are the same as those noted for the finite difference/piston theory analysis, but no apparent wrinkling is noted at the lower altitudes.

Two CFD solutions and their respective grids are shown in figures 13 and 14 . Here, the membrane occupies the lower surface between $x=0$ and $x=10$. The grid extends upstream and downstream of the membrane 8 grid points in each direction. The membrane deformation built into these grids was obtained with CFL3D coupled with NASTRAN, and they are the same as the deformation shown in figure 10 at the 


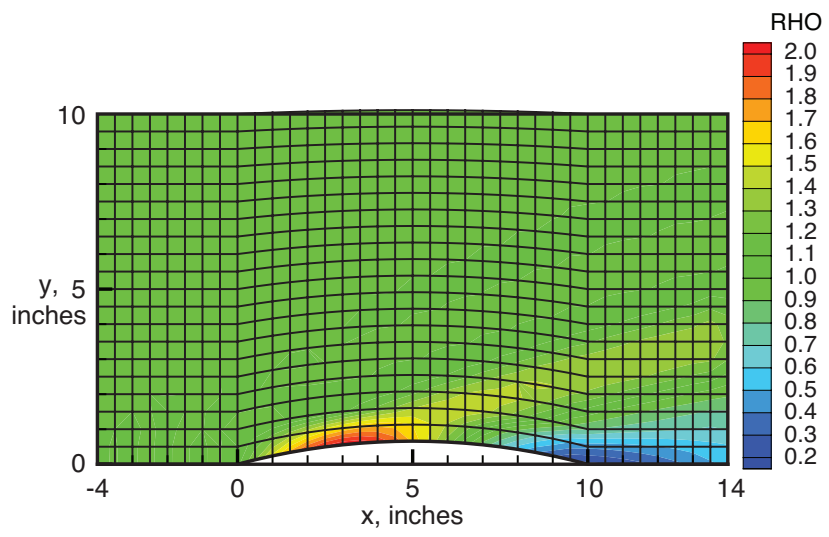

Fig. 13 CFL3D static aeroelastic solution grid with nondimensional density contours, $M=5$, Altitude $=200,000$ feet, $\Delta P_{o}=1.0 \mathrm{psi}$, and Pretension $=10 \mathrm{lbf} / \mathrm{in}$.

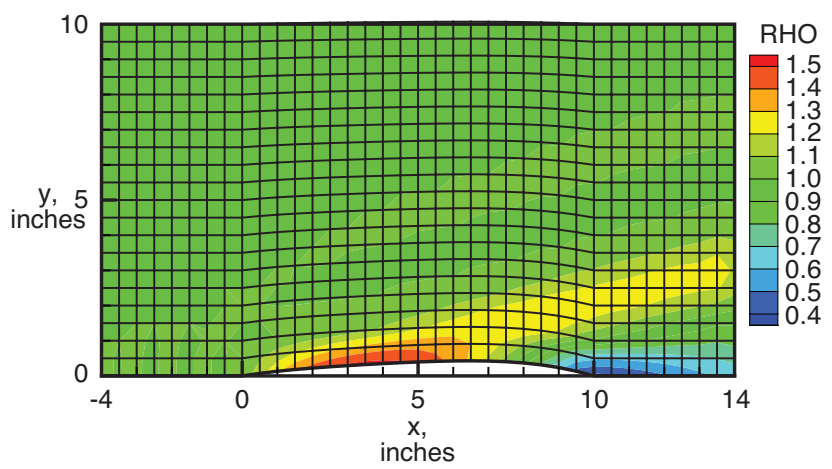

Fig. 14 CFL3D static aeroelastic solution grid with nondimensional density contours, $M=5$, Altitude $=60,000$ feet, $\Delta P_{o}=1.0$ psi, and Pretension $=10 \mathrm{lbf} / \mathrm{in}$.

200,000 and 60,000 feet altitudes. These contour plots show the existence of a dissipated shock wave at the leading edge of the membrane indicating the need for a more refined grid.

\section{Membrane Dynamic Aeroelasticity}

This section of the paper will examine the dynamic aeroelastic behavior of 2-d membranes. The dynamic aeroelastic analysis begins where the static aeroelastic analysis ends. As has already been described, for a given Mach number and altitude, a converged static aeroelastic solution is obtained. Then, a second numerical simulation is performed with artificial damping terms removed and the static aeroelastic solution perturbed slightly to assess stability. If the oscillations decay, then the solution is deemed stable, and if they diverge, the solution is deemed unstable. In the case of the finite difference membrane analysis, 3rd order piston theory will be used with the same analysis procedure as has already been described. As of this writing, a flutter analysis with CFL3D is only performed modally although the capability exists to directly couple a structural solver and CFL3D. Thus, a CFL3D/NASTRAN modal flutter analysis procedure will be described next, followed by some preliminary flutter analyses.

\section{Modal Flutter Analysis Procedure}

The modal flutter analysis procedure has many steps that can most easily be described in the following enumerated list.

1. Obtain a converged, nonlinear static aeroelastic solution using the previously described loosely coupled NASTRAN SOL 106 and CFL3D static solution procedure.

2. Perform a NASTRAN SOL 103 analysis (normal modes analysis), using the final stiffness matrix from the preceding step.

3. Extract the frequencies and mode shapes from the NASTRAN SOL 103 output file. Put modal frequencies in CFL3D input file.

4. Create CFD grid with the membrane surface deformed into the converged static aeroelastic shape from the final NASTRAN SOL 106 solution in step 1 .

5. Perform CFL3D analysis (irestart $=0$ ) with modal deformation turned off (moddfl $=-1)$.

6. Extract converged generalized forces from the CFL3D output, put these values in the CFL3D input file as input parameter gf0. Since the static aeroelastic shape is built into the grid, this step ensures that the pressure forces and internal stresses initially sum to zero so that no static aeroelastic deformation is obtained within CFL3D.

7. Restart CFL3D (irestart=1) with modal deformation turned off (moddfl=-1). After this run, net generalized forces should be near zero. Without this step, a transient in the generalized force will be introduced.

8. Restart CFL3D (irestart=1) with modal deformation turned on (moddfl $=0$ ) and a large value of modal damping $(\mathrm{damp}=0.99)$. This will remove any generalized coordinate transient associated with the net generalized force not being identically zero.

9. Restart CFL3D (irestart=1) with modal deformation turned on (moddfl $=0)$, modal damping set to zero $($ damp $=0.0)$, and a perturbation value for the modal velocities $\left(\mathrm{x} 0\left(2^{*} \mathrm{n}\right)=0.05\right)$. This step in the procedure is where stability is determined. 


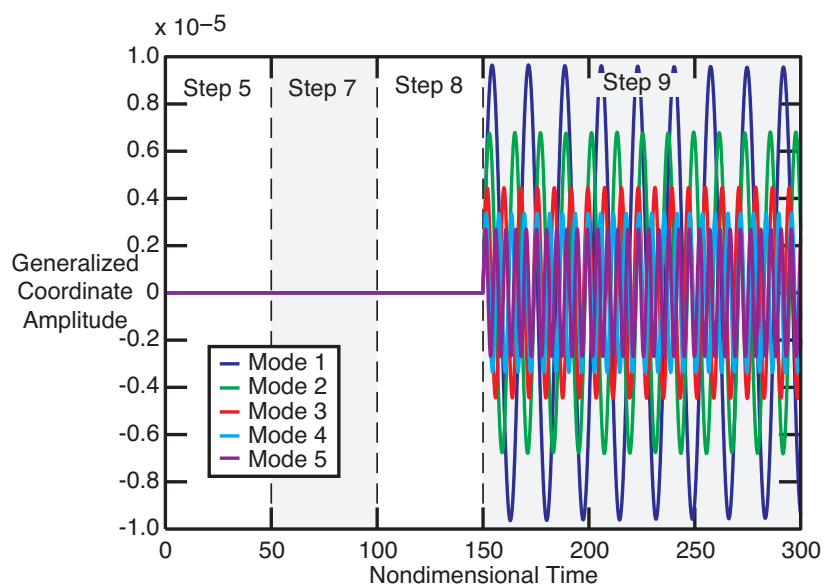

Fig. 15 Generalized coordinate time histories from CFL3D using NASTRAN 106/103 normal modes and frequencies, $M=5.0$, Altitude $=$ 200,000feet, Pretension $=10 \mathrm{lbf} / \mathrm{in}, \Delta P_{o}=$ $1.0 \mathrm{psi}$, and $\Delta x=0.05 \mathrm{in}$.

Figure 15 shows a set of generalized coordinate time histories resulting from the application of this procedure. The initial and three subsequent CFL3D restart runs have been identified with their appropriate step numbers. Note that only in the final run do the generalized coordinate values change. For this specific analysis (altitude $=200,000$ feet) the dynamic pressure is low and the generalized coordinate response is stable and largely undamped.

It should be pointed out that in the typical usage of CFL3D for flutter analysis, the normal modes and their associated frequencies don't change based on altitude or dynamic pressure. Here, the frequencies and mode shapes can change as a function of altitude. The first five modal frequencies are plotted versus altitude in figure 16. The modal frequencies drop as a result of decreasing altitude. To examine the behavior of the mode shapes, figure 17 shows the scaled vertical displacement of mode 1 plotted versus the static aeroelastic location of the nodes in the $\mathrm{x}$-direciton (initial nodal $\mathrm{x}$-value plus its static aeroelastic increment). Here modal displacement is seen to be a relatively weak function of altitude. Note that these modal displacement are the displacements about the static aeroelastic solution that has been previously shown to be a stronger function of altitude.

\section{Membrane Flutter Analyses}

Applying the procedure just described at various altitudes, it is possible to identify the flutter onset condition. Figures 18 and 19 show the time histories of the generalized coordinates for the altitudes of 80,000 and 60,000 feet, respectively. The generalized coordinate time histories at 80,000 feet and above showed stable, mild growth, or mild decay in amplitude. In

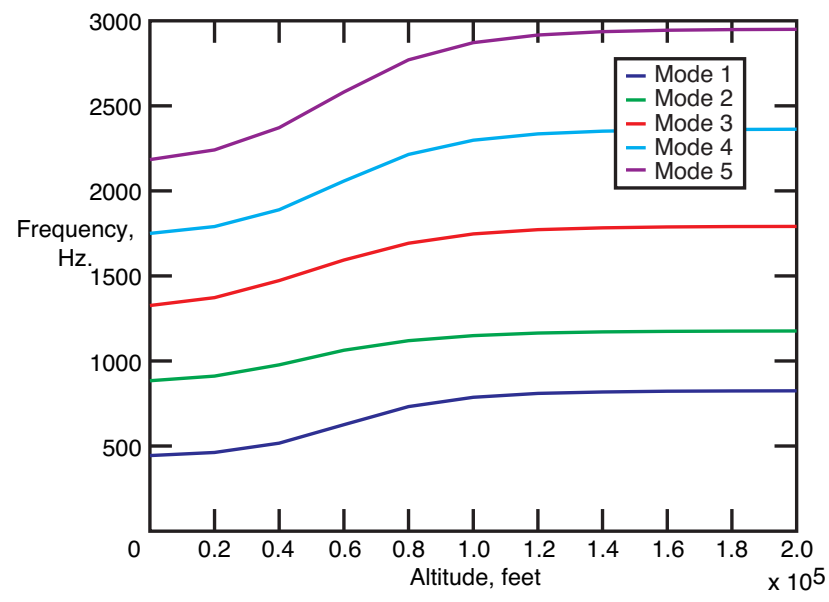

Fig. 16 NASTRAN SOL 106/103 modal frequencies as a function of altitude, $M=\mathbf{5 . 0}$, Pretension $=10 \mathrm{lbf} / \mathrm{in}, \Delta P_{o}=1.0 \mathrm{psi}$, and $\Delta x=0.05$ in.

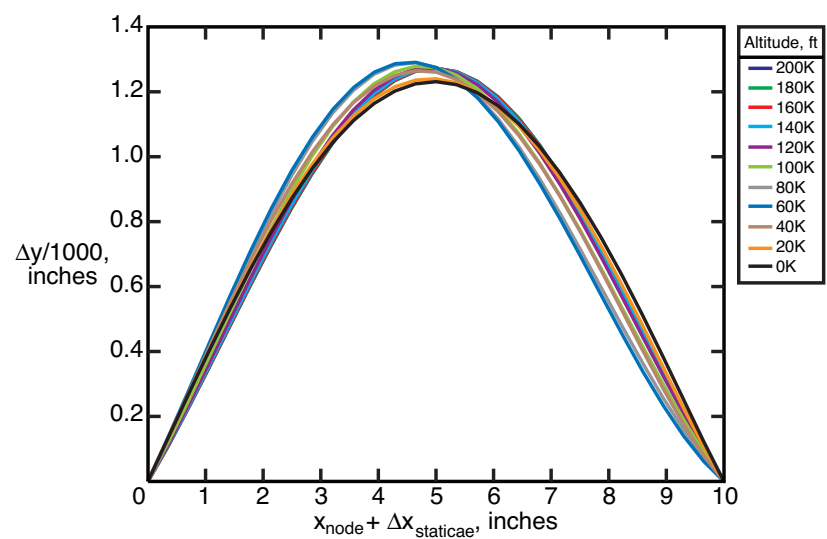

Fig. 17 NASTRAN SOL106/103 mode 1 displacements from static solution, $M=\mathbf{5 . 0}$, Pretension $=10 \mathrm{lbf} / \mathrm{in}, \Delta P_{o}=1.0 \mathrm{psi}$, and $\Delta x=0.05$ in.

the case of figure 18, the amplitude of mode 3 is increasing at a linear rate. For 60,000 feet, mode 3 grew at a more exponential rate. Typically, in this type of flutter analysis, at flutter onset several modes increase in amplitude at a single frequency. Here, at 60,000 feet, modes 3 and 4 are increasing in amplitude but their frequencies are not the same. It is probably worth pointing out that there are some important differences between a typical CFL3D flutter analysis and the analyses in this paper. In most applications of CFL3D to flutter analysis, the same mode shapes and frequencies are used for all altitudes/conditions. Here, in addition to the static aeroelastic solution changing significantly, the mode shapes and frequencies are also changing with altitude. Additional study will be required to understand the implications of these new analysis features and the specific results obtained.

Simulations for assessing dynamic aeroelastic stabil- 


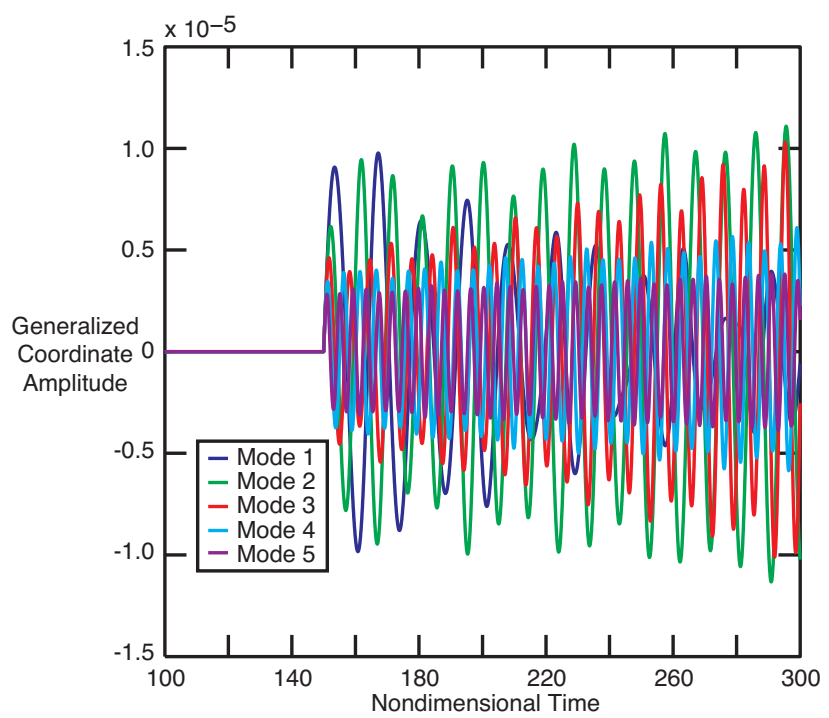

Fig. 18 Generalized coordinate time histories from CFL3D using NASTRAN 106/103 normal modes and frequencies, $M=5.0$, Altitude $=80,000$ feet, Pretension $=10 \mathrm{lbf} / \mathrm{in}, \Delta P_{o}=1.0 \mathrm{psi}$, and $\Delta x=$ $0.05 \mathrm{in}$.

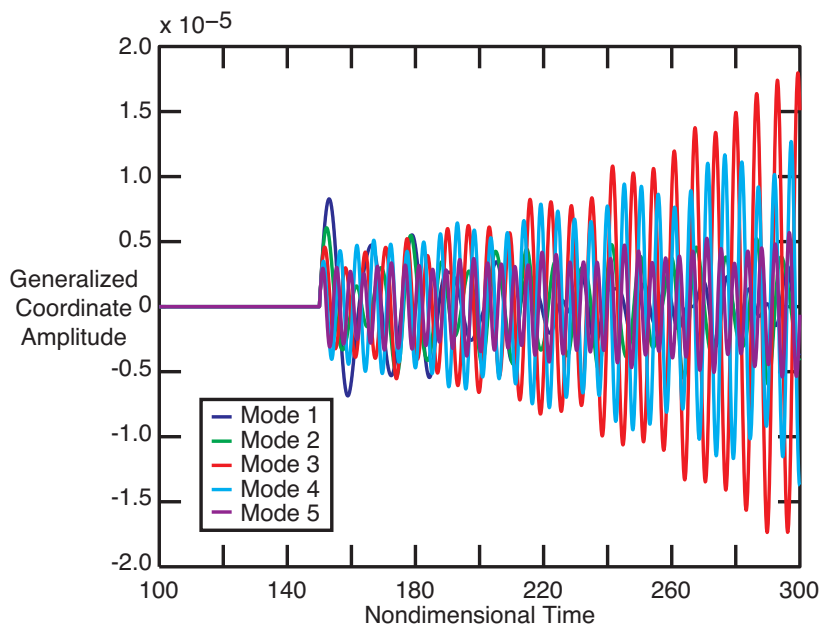

Fig. 19 Generalized coordinate time histories from CFL3D using NASTRAN 106/103 normal modes and frequencies, $M=5.0$, Altitude $=60,000 \mathrm{feet}$, Pretension $=10 \mathrm{lbf} / \mathrm{in}, \Delta P_{o}=1.0 \mathrm{psi}$, and $\Delta x=$ $0.05 \mathrm{in}$.

ity using the finite difference scheme coupled with 3rd order piston theory were also performed at the various altitudes. Figure 20 shows the vertical displacement time history for the approximate center point of the membrane $(\mathrm{i}=11)$ at the various altitudes. When the altitude is 40,000 feet or greater the solution is stable. For altitudes of 20,000 feet and below the solutions are unstable. The proper interpretation of this result is, however, unclear. Initially, the response grows in a smooth manner. One might interpret this result as flutter onset, but due to the nonlinearities, a limit cy-

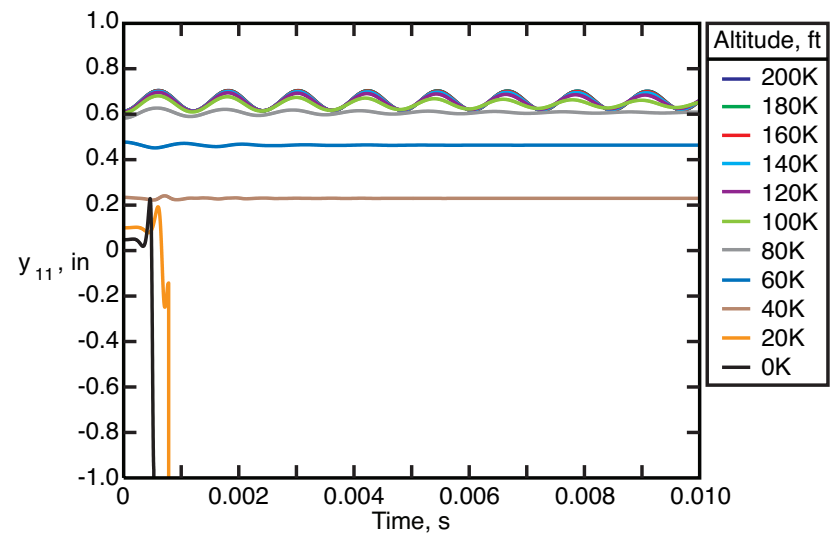

Fig. 20 Time history of vertical displacement of membrane center point $\left(y_{i=11}\right)$ using finite difference structural model and 3rd order piston theory aerodynamics, $M=5.0$, Pretension $=10 \mathrm{lbf} / \mathrm{in}$, $\Delta P_{o}=1.0 \mathrm{psi}$, and $\Delta x=0.05 \mathrm{in}$.

cle oscillation (LCO) might be expected. Instead of a "stable" LCO, the solution blows up after a few cycles. This problem may be associated with a limitation in the ability of the finite difference scheme to handle large geometric nonlinearities, and it should also be noted that the static aeroelastic solutions associated with the conditions where the "instabilities" occurred showed some wrinkling-like behavior. If the exact point of instability onset is identified (between 40,000 and 20,000 feet) a stable LCO may be obtained.

To summarize the flutter analyses performed so far, hard flutter onset is between 80,000 and 60,000 feet for the CFL3D modal flutter analysis and between 40,000 and 20,000 feet for the finite difference/piston theory analysis. Also, at the intermediate altitudes (40,000 to 100,000 feet) a large amount of aerodynamic damping is introduced in the finite difference/piston theory analyses, while little or no aerodynamic damping appears to be present for any of the CFL3D modal analyses. Clearly, additional study will be required to fully understand membrane flutter and these preliminary results. It is also apparent that the viability of modal based flutter analysis versus a fully nonlinear structural simulation cannot yet be assessed, as the analyses performed so far utilize different aerodynamic methods.

\section{Concluding Remarks}

The aeroelastic analysis of a thin-film ballute is a technical challenge. One of the challenges is the modeling of the ballute's complex, 3-dimensional membrane structure. A membrane with large deflections is nonlinear and it has the tendency to wrinkle, complicating both the structural analysis as well as the associated aerodynamic analysis. There are a number of possible ways to model the membrane including finite difference, finite element, and modal representations. The 
modal representation must be linearized about a nonlinear static solution. Commercial finite element codes exist that can model membrane structures, but developing a close-coupled aeroelastic analysis capability will not be possible due to the proprietary nature of these codes. Aeroelastic analysis schemes based on close and loose coupling with appropriate flow solvers will both need to be investigated to verify and validate the various approaches.

This paper proposed a series of steps leading to the development of a membrane flutter analysis capability. A building block approach is proposed in which increasing levels of complexity are added. Initially, the simplest possible structural and aerodynamic models are considered. This approach should allow for a thorough understanding of the physics and numerics associated with each step.

This paper examined a relatively simple, 2dimensional membrane structure. A finite difference representation of the membrane was developed that captured membrane pretension and static pressure difference across the membrane. This model was then used to obtain nonlinear static solutions with various levels of pretension and static pressure difference. A NASTRAN membrane model was developed and nonlinear static solutions were obtained and compared with those from the finite difference model. These static analyses were in excellent agreement. Additionally, some dynamic validation studies were also presented. Here, frequencies from spectral analysis of the finite difference time traces were compared with the frequencies from linear theory and NASTRAN SOL 106/103. These studies further validated the finite difference membrane model.

Third order piston theory aerodynamics was included in the membrane finite difference model, and a series of static aeroelastic solutions was obtained at various altitudes for fixed Mach number. At the lower altitudes, some of these solutions appeared wrinkled. A procedure was developed to couple both the NASTRAN nonlinear static solution and the finite difference scheme with CFL3D. Here, the NASTRAN and finite difference solution were in excellent agreement.

Using the converged static aeroelastic solutions as a starting point, dynamic stability was investigated. Here again, altitude was varied for a fixed Mach number with solution time histories being examined at each condition. Two analyses types were considered: 1) The membrane finite difference scheme with piston theory aerodynamics, and 2) NASTRAN SOL 106 and SOL 103 mode shapes and frequencies in CFL3D. At a fixed Mach number, both methods provided estimates of the flutter onset altitude. In contrast to the static analyses, these flutter analyses were not in good agreement. The flutter onset altitudes were different as were the damping characteristics of the time traces as a function of altitude. Further study will be required to fully understand the implications of these preliminary results.

There is clearly much additional work to be done to gain a good understanding of the aeroelastic characteristics of thin membrane structure, and further study and method development will need to be performed to better understand the dynamic aeroelastic behavior of thin membranes. This work includes CFD and structural grid convergence studies. Parametric studies where the effects of membrane geometry, static pressure difference, and pretension are considered. The finite difference equations need to be incorporated into CFL3D to make a proper comparison between structural modeling approaches, and the use of Navier Stokes equations in the flow solver should also be considered. Ultimately, a hypersonic CFD flow solver will need to be used.

\section{References}

${ }^{1}$ Rohrschneider, R. R. and Braun, R. D., "A Survey of Ballute Technology for Aerocapture," Proceedings of the 3rd International Planetary Probe Workshop, June 2005.

${ }^{2}$ Johnson, L., Alexander, L., Baggett, R., Bonometti, J., Herrmann, M., James, B., and Montgomery, S., "NASA's InSpace Propulsion Technology Program: Overview and Update," 40th AIAA/ASME/SAE/ASEE Joint Propulsion Conference and Exhibit, No. AIAA-2004-3841, July 2004.

${ }^{3}$ Gnoffo, P. A. and Anderson, B. P., "Computational Analysis of Towed Ballute Interactions," 8th AIAA/ASME Joint Thermophysics and Heat Transfer Conference, No. AIAA 20022997, June 2002.

${ }^{4}$ Hornung, H. G., "Hypersonic Flow Over Bodies in Tandem and its Relevence to Ballute Design," 31st AIAA Fluid Dynamics Conference, No. AIAA 2001-2776, June 2001.

${ }^{5}$ Buck, G. M., "Testing of Flexible Ballutes in Hypersonic Wind Tunnels for Planetary Aerocapture," 44th AIAA Aerospace Sciences Meeting and Exhibit, No. AIAA-2006-01319, Jan. 2006.

${ }^{6}$ Jenkins, C. H. and Leonard, J. W., "Nonlinear dynamic Response of Membranes: State of the Art," Applied Mechanis Review, Vol. 44, No. 7, July 1991.

${ }^{7}$ Jenkins, C. H., "Nonlinear dynamic Response of Membranes: State of the Art - Update," Applied Mechanis Review 1996 Suplement, Vol. 48, No. 10, Oct. 1996.

${ }^{8}$ Main, I. G., Vibrations and Waves in Physics, 1993.

${ }^{9}$ Sparling, B. F. and Davenport, A. G., "Nonlinear Dynamic Behavior of guy Cables in Turbulent Winds," Canadian Journal of Civil Engineering, Vol. 28, 2001, pp. 98-110.

${ }^{10}$ Anderson, W. J., "Dynamic Instability of a Cable in Incompressible Flow," AIAA/ASME/SAE 14th Structures, Structural Dynamics, and Materials Conference, March 1973.

${ }^{11}$ de Oliveira Pauletti, R. M., Guirardi, D. M., and Deifeld, T. E. C., "Argyris' Natural Membrane Finite Element Revisited," International Conference on Textile Composites and Inflatable Structures, Structural Membranes, 2005.

${ }^{12}$ Vanden-Broeck, J.-M., "Nonlinear Two-Dimensional Sail Theory," Physics of Fluids, Vol. 25, No. 3, March 1982.

${ }^{13}$ Maitre, O. L., Huberson, S., and Cursi, E. S. D., "Unsteady Model of Sail and Flow Interaction," Journal of Fluids and Structures, Vol. 13, 1999. 
${ }^{14}$ Nielson, J. N., "Theory of Flexible Aerodynamic Surfaces," Journal of Applied Mechanics, , No. 63-APM-29, 1963.

${ }^{15}$ Newman, B., "Aerodynamic Theory for Membranes and Sails," Progress in Aerospace Sciences, Vol. 24, 1987.

${ }^{16}$ Smith, R. and Shyy, W., "Computation of Aerodynamic Coefficients for a Flexible Membrane Airfoil in Turbulent Flow: A Comparison with Classical Theory," Physics of Fluids, Vol. 12, No. 8, Dec. 1996.

${ }^{17}$ Shyy, W. and Smith, R., "A Study of Flexible Airfoil Aerodynamics with Application to Micro Aerial Vehicles," 28th AIAA Fluid Dynamics Conference, No. AIAA-1997-1933, June 1997.

${ }^{18}$ Lillberg, E., Kamakoti, R., and Shyy, W., "Computation of Unsteady Interaction Between Viscous Flows and Flexible Structure with Finite Inertia," 38th Aerospace Sciences Meeting and Exhibit, No. AIAA 2000-0142, Jan. 2000.

${ }^{19}$ Smith, R. and Shyy, W., "Computation of Unsteady Laminar Flow Over a Flexible Two-Dimensional Membrane Wing," Physics of Fluids, Vol. 9, No. 7, Sept. 1995.

${ }^{20}$ Shyy, W. and Smith, R., "Computation of Laminar Flow and Flexible Structure Interaction," Computational Fluid Dynamics Review 1995, 1995.

${ }^{21}$ Lian, Y., Shyy, W., Viieru, D., and Zhang, B., "Membrane Wing Aerodynamics for Micro Air Vehicles," Progress in Aerospace Sciences, 2003.

${ }^{22}$ Lian, Y., Shyy, W., and Haftka, R., "Shape Optimization of a Membrane Wing for Micro Air Vehicles," 41st Aerospace Sciences Meeting and Exhibit, No. AIAA 2003-0106, Jan. 2003.

${ }^{23}$ Lian, Y., Shyy, W., and Ifju, P. G., "A Computational Model for Coupled Membrane-Fluid Dynamics," 32nd AIAA Fluid Dynamics Conference and Exhibit, No. AIAA 2002-2972, June 2002.

${ }^{24}$ Johnston, J. D., Blandino, J. R., and McEvoy, K., "Analytical and Experimental Characterization of Gravity Induced Deformations in Subscale Gossamer Structures," 45th AIAA/ASME/ASCE/AHS/ASC Structures, Structural Dynamics and Materials Conference, No. AIAA 2004-1817, April 2004 .

${ }^{25}$ Papa, A. and Pellegrino, S., "Mechanics of Systematically Creased Thin-Film Membrane Structures," 46th AIAA/ASME/ASCE/AHS/ASC Structures, Structural Dynamics and Materials Conference, No. AIAA 2005-1975, April 2005.

${ }^{26}$ Tessler, A., Sleight, D. W., and Wang, J. T., "Nonlinear Shell Modeling of Thin Membranes with Emphasis on Structural Wrinkling," 44th AIAA/ASME/ASCE/AHS/ASC Structures, Structural Dynamics and Materials Conference, No. AIAA 2003-1931, April 2003.

${ }^{27}$ Lee, K. and Lee, S. W., "Structural Analysis of Scientific Balloons Using Assumed Strain Formulation Solid Shell Finite Elements," 46th AIAA/ASME/ASCE/AHS/ASC Structures, Structural Dynamics and Materials Conference, No. AIAA 2005-1802, April 2005.

${ }^{28}$ Woo, K. and Jenkins, C. H., "Global/Local Analysis Strategy for Partly Wrinkled Membrane," 46th AIAA/ASME/ASCE/AHS/ASC Structures, Structural Dynamics and Materials Conference, No. AIAA 2005-1977, April 2005.

${ }^{29}$ Sleight, D. W. and Muheim, D. M., "Parametric Studies of Square Solar Sails Using Finite Element Analysis," 45th AIAA/ASME/ASCE/AHS/ASC Structures, Structural Dynamics and Materials Conference, No. AIAA 2004-1509, April 2004.

${ }^{30}$ Greschik, G., Palisoc, A., Cassapakis, C., Veal, G., and Mikulas, M. M., "Sensitivity Study of Precision Pressurized Membrane Reflector Deformations," AIAA Journal, Vol. 39, No. 2, Feb. 2001.
${ }^{31}$ Smalley, K. B., Tinker, M. L., and Fischer, R. T., "Investigation of Nonlinear Pressurization and Modal Restart in MSC/NASTRAN for Modeling Thin Film Inflatable Structures," 42nd AIAA/ASME/ASCE/AHS/ASC Structures, Structural Dynamics, and Materials Conference and Exhibit, No. AIAA 2001-1409, April 2001.

${ }^{32}$ Sakamoto, H. and Park, K., "Design Parameter Effects for Wrinkle Reduction in Membrane Space Structures," 46th AIAA/ASME/ASCE/AHS/ASC Structures, Structural Dynamics and Materials Conference, No. AIAA 2005-1974, April 2005.

${ }^{33}$ Sutjahjo, E., Su, X., Abdi, F., and Taleghani, B., "Dynamic Wrinkling Analysis of Kapton Membrane Under Tensile Loading," 45th AIAA/ASME/ASCE/AHS/ASC Structures, Structural Dynamics and Materials Conference, No. AIAA 2004-1738, April 2004.

${ }^{34}$ Tessler, A., Sleight, D. W., and Wang, J. T., "Effective Modeling and Nonlinear Shell Analysis of Thin Membranes Exhibiting Structural Wrinkling," Journal of Spacecraft and Rockets, Vol. 42, No. 2, April 2005.

${ }^{35}$ Dowell, E. H., "Panel Flutter: A Review of the Aeroelastic Stability of Plates and Shells," AIAA Journal, Vol. 8, No. 3, 1970.

${ }^{36}$ Mei, C., Abdel-Motagaly, K., and Chen, R., "Review of Nonlinear Panel Flutter at Supersonic and Hypersonic Speeds," Applied Mechanics Reviews, Vol. 52, No. 10, 1999.

${ }^{37}$ Bisplinghoff, R. L. and Ashley, H., Principles of Aeroelasticity, 1962.

${ }^{38}$ Spriggs, J., Messiter, A., and Anderson, W., "Membrane Flutter Paradox-An Explanation by Singular Perturbation Methods," AIAA Journal, Vol. 7, No. 9, Sept. 1969.

${ }^{39}$ Johns, D., "Supersonic Membrane Flutter," AIAA Journal, Vol. 9, No. 5, May 1971.

${ }^{40}$ Ellen, C., "Approximate Solutions of the Membrane Flutter Problem," AIAA Journal, Vol. 3, No. 6, June 1965.

${ }^{41}$ Liu, D. D., Chen, P. C., Tang, L., and Chang, K. T., "Hypersonic Aerothermodynamics/Aerothermoelastics Methodology for Reusable Launch Vehicles/TPS Design and Analysis," 41st Aerospace Sciences Meeting and Exhibit, No. AIAA 2003897, Jan. 2003.

${ }^{42}$ Hui, W. H. and Liu, D. D., "Unsteady Unified Hypersonic-Supersonic Aerodynamics : Analytical and Expedient Methods for Stability and Aeroelasticity," 44th AIAA/ASME/ASCE/AHS Structures, Structural Dynamics and Materials Conference, No. AIAA 2003-1964, April 2003.

${ }^{43}$ Gnoffo, P. A., McCandless, R. S., and Yee, H. C., "Enhancements to Program LAURA for Computation of ThreeDimensional Hypersonic Flow," AIAA 25th Aerspace Sciences Meeting, No. AIAA 87-0280, Jan. 1987.

${ }^{44}$ Kleb, W. L., Nielsen, E. J., Gnoffo, P. A., Park, M. A., and Wood, W. A., "Collaborative Software Development in Support of Fast Adaptive AeroSpace Tools (FAAST)," 16th AIAA Computational Fluid Dynamic Conference, No. AIAA 2003-3978, June 2003.

${ }^{45}$ Krist, S. L., Biedron, R. T., and Rumsey, C. L., "CFL3D User's Manual (Version 5.0)," NASA-TM 1998-208444, June 1998.

${ }^{46}$ Bartels, R. E., "CFL3D Version 6.4 General Usage and Aeroelastic Analysis," NASA-TM 2006-214301, 2006.

${ }^{47}$ McNamara, J. J., Friedmann, P. P., Powell, K. G., Thuruthimattam, B. J., and Bartels, R. E., "Threedimensional Aeroelastic and Aerothermoelastic Behavior in Hypersonic Flow," 46th AIAA/ASME/ASCE/AHS/ASC Structures, Structural Dynamics and Materials Conference, April 2005 .

${ }^{48}$ Bartels, R. E., Moses, R. W., Scott, R. C., Templeton, J. D., Cheatwood, F. M., Gnoffo, P. A., and Buck, G. M., "A Proposed Role of Aeroelasticity in NASA's New Exploration 
Vision," International Forum on Aeroelasticity and Structural Dynamics, No. IF-013, 2005.

${ }^{49}$ Libhthill, M. J., "Oscillating Airfoils at High Mach Number," Journal of Aeronautical Sciences, Vol. 20, No. 6, June 1953.

50 "Earth Atmosphere Model, Imperial Units," http://www.grc.nasa.gov/WWW/K-12/airplane/atmos.html. 